\title{
TOTIUS SE SIENING VAN DIE CALVINISTIESE DIGTER AS SIENER.*
}

\section{Susanne van Deventer}

\begin{abstract}
In his lecture, De dichter als ziener (1911) Totius sees the Calvinist poet as a prophet and a seer who sees the invisible, who discovers profound truths in the mundance, everyday reality. Any object may be used as material, and the poet has to make a penetrating study of his surroundings. The deeper and more profound insights that the poet is able to record must be conveyed to his fellowment. The resulting work of art will then ultimat ely reflect the Divine in which it had its origin.
\end{abstract}

A study of Totius' private library has revealed that the poet read widely about the nature of the prophet, including the works of Adlers, Rabus and Worsfold, amongst others. In his view of the poet Totius was greatly influenced by his Amsterdam professor, Prof. J. Woltjer, to whose works most of Totius' views on the nature of poetry can be traced.

\section{ARS POETICA}

Totius se ars poetica is verwoord in sy referaat op die jaarvergadering van die Suid-Afrikaanse Akademie vir Wetenskap en Kuns in 1911, ** waarin hy sy siening van die digter en die digterskap uiteensit. Hierdie lesing is belangrik nie net vir Totius se oeuvre nie maar ook vir die Afr'iaanse literêre teorie in die algemeen. Die opstel van 1911 word deur menr $\quad$ ibeskou as die begin van die Afrikaanse literêre teorie. "Die heel eerste literêr-teoretiese opstel van 'n Afrikaanse digter", noem prof. T.T. Cloete hierdie belangrike referaat.

- Verwerking van 'n hoolsluk uil die ongepublisecrde proefskrif, WrRKIIKIIIII) EN WAARHIEION(INI)ERS(OEK NAIJIF SIMBOIIEK BY I(IIIIS, UP, 1982. Die studie is onder andere inel behulp van geldelike bysland van die RGN onderneem. Menings wat in hierdie drtikel uitgespreek is en gevolgtrekkings wadrtoe geraak is, is die van die skrywer en moel nie as die van die RCN beskou word nie.

* Opgeneem in:
(i) IAARHOEK VAN DIt S.A. AKADEMIt, II, 1911, p. 53-59
(ii) DIE V(JLKSTEM, $\$ \&$ (3924), 4, Julie 7, 1911.
(iii) DIE IIUISGENOOI, 31 (1 300), Feb 21, 1947 p. 33.
(iv) P.J Nienaber red 1948 TOTIUS. DIGIER EN PROFEET
A.P.B., Johannesburg P. 229
(v) Merwe Scholta red 1977 DIE LEWENDE TOTIUS, Talelberg p. 1
(vi) Totius, 1977 VFRSAMEI DL WERKE, Deel 10, Jalelberg, p. 1-7 (verlaal).

Koers, $48(2) 1983$ 


\section{Van Deventer}

"Fk is van mening dat hierdie lesing 'n belangrike dokument in die Afrikaanse nadink oor die aard van die literatuur is ... die eerste welbewuste baken op die pad van die Afrikaanse literatuurteorie is," en "'n belangrike bydrae ... in die ontwikkeling van die denke oor die dinge wat aan die litcratuurten gronslag lề", sê prof. F.I.J. van Rensburg en voeg by: "Die fondament van die Afrikaanse literêre teorie word hier op onmiskenbare wyse .. gelê". Hy noem Totius na aanleiding hiervan "ons eerste literêre teoretikus".

Maar die lesing is ook belangrik by die bestudering van Totius se poësie, want hier sit hy sy siening omtrent die simboliseringsproses in die poësie uiteen: hier gee hy sy mening omtrent die digter as Calvinistiese siener wat in die aardse sienlike dinge 'n dieper waarheid vind: vertel hy dat alle aardse dinge "een idee" dra: dat die digter nie abstraksies najaag nie maar lewende realiteite wat "wandelen, dansen, springen en zingen voor zijn verhelderd oog" en dat hy sy digkuns sien as 'n bestudering van "de gedachte Gods".

\section{DRIE EISE}

Totius bring in sy eerste paragraaf drie beginsels of eise na vore, naamlik eise aan die digter as subjek, eise aan die digstof as objek en laastens die poësie self as eenheid van subjek en objek.

Samevattend kom Totius se siening van die digter hierop neer dat die digter met die Ou-Testamentiese siener vergelyk word: dat die digter met die oog van die verstand meer sien as wat die gewone mens sien: dat verborge warhede sodoende aan hom geopenbaar word. Aangesien die eerste mens die sienersgawe deur die sondeval verloor het, is hierdie insig nou slegs deur die genade van God moontlik en is dit ook net van korte duur. Die digter moet die aardse dinge om hom eers deeglik verken (wêreldaanskouer wees), en enige gegewe kan as stof gebruik word.

Sy eise aan die digstof bepaal dat alle lewensdinge rondom die digter draers van dieper waarhede is: lewe en beweging kenmerke van die poësie is en dat die dieper insig wat die aardse dinge aan die digtervertoon, aan ander oorgedra moet word.

Eise aan die digkuns bepaal dat die beeld of simbool die skakel tussen die digter en die skepping is of, anders gestel: die openbaarmaking van die dieper waarhede wat in die stoflike gevind word, geskied deur die instrument van die taal: die oordra van wat die digter in die aardse vind, is 'n taak wat slegs met groot moeite volbring kan word. Die oor kom die digter ook te hulp in die ontdekkingsproses, en die uiteindelike produk of kunswerk moet draer wees van die Goddelikheid waarult dit ontstaan het. 
In sy bespreking verwys Totius na die kunsteoretiese opvattings van onder andere Schiller, Herder, Dante, Vondel, Lessing, Spencer, Aristoteles, Plato, Addison en Lampert en weerlê hulle siening of stem gedeeltelik daarmee saam. Hy verwys ook na uitsprake van skrywers soos Woltjer, Belpaire, Herder, Rabus, Worsfold en Feith.

\subsection{Eise Aan Die Digter}

Die eerste beginsel of eis in die referaat betrek die digter. Volgens Totius is die digter eerstens siener in die Bybelse sin van die woord, siener soos byvoorbeeld Samuel, 'n profeet van die Here wat dinge kan sien waarvan die gewone mens nie bewus is nie.

In die Voorwoord tot die Totiushuldigingsnommer van Die Huisgenool (21 Februarie 1947) word daarop gewys dat Totius soms vates genoem is. Met hierdie woord het die Romeine 'n profeet, siener of digter aangedui. Vir die skrywer van die Voorwoord (die redakteur, M.H. Viljoen) is Totius se beskouing nie die van die Ou-Testamentiese profeet nie. Hy sê: "Ons dink hier natuurlik nie aan die toornende Ou-Testamentiese profeet nie, maar eerder'n man wat toegerus vir die stryd van vandag met liefde en teerheid, maar ook met strengheid as die omstandighede dit vereis, sy boodskap bring. En hierdie boodskap is dat ons as Calvinistiese volk 'n sekere roeping het oln aan die suidpunt van Afrika te vervul".

Ek meen dat die uitspraak grootliks waar is, maar vind $\log$ in Totius se siener eienskappe wat met die van die Ou-Testamentise siener ooreenstem. Soos die Bybelse siener sien die digter volgens Totius ook meer en dieper waarhede as die gewone mens, en tweedens is dit sy taak om die dieper waarhede aan sy volk te verkondig. Trouens, Totius self lê die verband tussen die digter en die Ou-Testamentiese siener deur in hierdie artikel oor die digter as siener na Samuel te verwys. In sy preke verwys Totius ook na ander Ou-Testamentiese profete en hul besondere sienersgawe. In sy Ou-Testamentiese preke (Totius, 1960, dl. 4: 32) praat hy van Henog as profeet van die Here en noem hy ook die profetes Debora. Christus self word deurgaans in die Ou- en NuweTestamentiese preke as die Groot Profeet beskou.

Om siener te wees beteken meer as om te kan sien. Die profeet of siener kan meer sien as die menslike oog: hy sien "things invisible to mortal sight", soos Milton deur Totius in sy referaat aangehaal word. Die digter sien met die oog van die verstand ("the mind through all her powers/ Irradiate there plant eyes ..."), en derhalwe is die paradoks waar dat "wie also . . ziet is ziende, ook met het blinde zicht", want "Ziener-zijn is iets anders dan ogen hebben". Hy sien die dieper waarhede in die aardse dinge, waarhede wat nie 


\section{Van Deventer}

vir die gewonde man beskore is om te sien nie. Totius is die "begenadigde siener van die onsienlike" wat "ewig waarhede vind" (Pretorius, 1977: 1).

Ook in sy teologiese artikels het Totius hieroor geskrywe. Cloete (1978: 6) wys daarop dat Totius in sy artikel "Drome droom" in deel 7 van die 1977 . $\checkmark$ rsamelde Werke van Moses praat as "een wat die Onsienlike sien". Die twee manne van God, naamlik losef, wat die Israeliete in Egipte ingelei het, en Moses, wat hulle daar uitgelei het, stem volgens Totius ooreen in die opsig dat hulle albei "ver in die oneindigheid ingestaar het".

Totius stel losef, die dromer, as voorbeeld vir sy lesers: "Laat ons tog droom die droom van ons deur God beglansde bestemming". In hierdie artikel het Totius dit ook oor die oog van die verstand, wat meer kan sien as die van die gewone mens, X-straaloë besit wat die onsienlike sien. Hier gebruik hy 'n ander beeld, naamlik die becld van "die verkyker van die Woord van God, wat deurdring in die oneindigheid in, totdat hy die oer-Son, naamlik God, weer vind". Tolius sluit "Drome droom" af met die verse van Hammenecker: "Gezegend Heer om t'licht van al die lichten, die naar uw glans hun zonnewezen richten, als naar hun bron. Gezegend om uw Licht, $\mathrm{O}$ Zon der zonnen, gezegend eerstbeginsel onbegonnen van alle Zon".

Totius sien as onontbeerlik by die Calvinistiese digter 'n duidelike visie, 'n meer waarneem as wat die gewone oog in die alledaagse sien. Die digter moet 'n indringende en deurdringende blik he, "het goddelik aanblikken van de anders schuilgaande wezenheden, die ons evenwel in bont-afwisselende menigvuldigheid omstuwen". Hy verlang van die digler "arends-ogen, zoeklichten, X-stralen, die boren in de geheimzinnigheid van de binnenkameren". Die digter moet dus meer sien in die aardse dinge, die dieper betekenis in die sienlike ontdek of, om dit in Oppermaniaanse idioom te stel, die engel uit die klip verlos.

In die gewone, alledaagse aardse dinge om hom vind die digter of siener dieper, verborge waarhede. "Die objekte buite hom (is) draers van sekere waarhede" (Venter, 1977: 136), en dit is "juis die onopvallende, die onopgesmukte", "die nederig-sinville, eenvoudige verskynsels in die natuur en die mensebestaan" (Dekker, 1964: 24) wat vir hom draers van dieper lewenswaarhede word. By Totius is "elke blommetjie, elke voël 'n kunswerk van die Heer" (Buning, 1934: 120).

Totius het 'n "menigvuldigheid eindige dinge", "stoflike dinge" om hom raakgesien en hy was "noulettend op die geringste dinge om hom heen" (Cloete, 1978: 7 . Hy sien 'n eenvoudige objek, byoorbveeld 'n boom, 'n put, 'n voëltjie ensovoorts, en deur die betragting daarvan word hy bewus van 'n 


\section{Tolius}

dieper lewenswaarheid. "Geen skeppingsding was in sy oë te gering om in liefde daarmee te verkeer en die ewigheidsgedagte daaruit te verlos nie, en geen ding was vir hom te gering om 'n gedagte Gods in hom verstoke te hou nie" (Dekker, 1964: 71). Totius se "bepeinsing van die dieper dinge van die lewe" het vir hom gestalte gekry in "die nederig-sinvolle eenvoudige verskynsels in die natuur en in die mensebestaan." C.M. van den Heever (S.J.) beweer: "Hy kyk deur die sienlike heen na die onsienlike, hy soek agter die aardse verskynsel na die wese van dinge, hy peins en probeer om die wonder van ons geestelike bestaan te deurgrond". "Hierdie gedagtes: ewigheidsgedagtes, skuil in alle skeppingsdinge" (Pretorius, 1977: 4). Sy sienersoog "lees in elke natuurverskynsel 'n betekenis wat vir die nie-kunstenaar verborge is" (Hartman, 1931: 150). Dit is die "goddelik aanblikken van de anders schuilgaande wezenheden, die ons evenwel in bont-afwisselende menigvuldigheid omstuwen", waarvan Totius in sy artikel praat.

'n Stelling wat 'n mens by die Calvinis Totius sal verwag, is dat die eerste mens goed en met die wonderlike sienersgawe geskep is maar dat hy dit as gevolg van die sondeval verloor het: "Doch daarna viel de zonde op zijn ziel en de nacht op zijn oog". So het die mens sy "kristalklaar zienersoog" verloor. Na die sondeval is dit slegs deur die genade van God ("bij de gratie Gods") en alleenlik vir 'n oomblik dat die kunstenaar of digter soms hierdie dieper insig of visie het. Nou is dit nog net die begenadigde enkeling wat soms momenteel hierdie dicper visie het: wat die voorreg het dat die genade "voor 'n ogenblik de vensters openzet van het donker geworden oog". Hy ontdek so die skoonheid van die adrdse dinge rondom hom: "hij sal vinden wat andere zoeken, hij zal de forma, vorm en schoonheid, ontdekken die schuil achter het anders ondoorschijnend-zichıbare".

Die mens wat blind geword het as gevolg van sy sonde in Adam, kan slegs sienersvermoë hê wanneer hy "genade van God ontvang het en begaaf is met $X$-straaloë of met arendsoë word die realiteit vir hom deurskynend soos 'n ruit en hy sien ewigheidsgedachtes daarin ..." (Cloete 1961: 94). Hierdie begenadigde siener is "de ware dichter".

So 'n digter sal klop en dit sal oopgaan, hy sal vind wat ander soek, hy sal die skoonheid in die alledaagse ontdek. Die digter is deur die Grieke "poictes" genoem; hy is maker, formeerder, skepper. Hy skep nuwe dinge "die niel waren voor die medemens".

Die digter is siener, sê Opperman, "nie slegs van die uiterlike werklikheid nie, maar . . . deur die werklikheid heen na die gedagıe van God". (Opperman, 1947: 24). Die kuns is volgens hierdie siening van Totius slegs genade wat goedgunstiglik deur God vir 'n kort ruk aan sy uitverkorenes gegee word. 


\section{Van Deventer}

Daarom seker ook dat die kunstenaar, alhoewel hy 'n skepper en maker is, homself volgens Totius nie tot 'n god mag verhef nie: "Wie zich alzo verheft, word weer neergeworpen".

'n Verdere eis wat aan die digter gestel word, is dat hy "wêreld-aanschouwer" moet wees. Soos Opperman en Van Wyk Louw dit later in hulle eie kunsteoretiese opstelle sou stel, besef Totius ook reeds baie vroeër dat die aardse dinge eers deeglik bekyk en verken moet word. "Wêreld-aanschouwer moet de dichter zijn". beweer Totius in hierdie lesing.

"Die literatuur wil die uiling van 'n volledige menslike lewe wees", sê N.P. van Wyk Louw (1939). Die kunstenaar moet homself volgens Opperman eers met die wêreld om hom heen vereenselwig, hy is 'n "verkleurmannetjie, hy neem die kleur van sy omgewing aan, word een daarmee, word die groen blaar en ook die droë takkie". Hy moet die "volle werklikheid" aandurf, hy sal dan "elke verskyning en verskynsel volwaardig, na sy wese peilend . . probeer uitbeeld", hy moet "elke verskynsel in sy eie reg en goddelikheid sien". Die digter moet die wêreld om hom verken, soos Opperman se Jorik landwaarnemer, landverkenner wees, want in elke natuurding of skeppingsding is daar 'n dieper betekenis wat daaruit raakgesien en gehaal kan word.

Soos hierdie twee groot digters na hom stel Totius in 1911 ook die eis (alhoewel hy nie daarop uitbrei nie) dat die digter "hom met die hele mens moet bemoei omdat alles met alles aamhang" (Cloete 1978: 3). Die lig van die Bybel het vir Totius geskyn "oor die hele wêreld en oor alle lewensterreine" (Van der Merwe, 1977: 66). Die digter moet waarnemer wees, eers die aards dinge om hom waarneem, die wêreld om hom raaksien en bekyk. Hierdie bekyk is 'n beskou van die "ganse kosmos".

Totius "het baie goed 'rondgekyk in hierdie wêreld waardeur hy op sy deurtog gereis het" (Cloete, 1961: 94). Hierdie opvatting dat die digter alles om hom moet verken, die aardse dinge eers leer ken voordat hy dit in sy kunswerk vaslê, is strydig met die idee van die kunstenaar in die geisoleerde ivoortoring. Totius was "om 'n literêre modewoord van vandag te gebruik, 'betrokke' by sowel die metafisiese as hierdie stoflike eindige, sienlike wêreld" en "gerig soos hy was op die Onsienlike, het hy deur die wêreld gegaan met wat hy self genoem het X-straaloë" (Cloete, 1978). Die digter moet volgens Totius se beskouing $k y k$ "in het hart van de levensdingen om ons heen". Hierdie lewensdinge besit nog 'n glans wat "nabloei van het Paradijs" is.

Nie net sekere dinge in die skepping is vir die poësie geskik nie. Alles kan gebruik word, want "de schepping is schoon en waar". Totius stem nie saam met Schiller dat dit van die subjek afhang of die gedig poëties goed of swak is 
nie, "want het schoon is niet subjektief". Die ganse skepping kan as digstof gebruik word. En dit is die digter se taak om dit in totaliteit te "bezien" en te "doorzien",

Hier herinner Totius aan die Nederlandse predikantdigter, Guido Gezelle. Wanneer die mens met sy innerlike oor en met die siel luister, spreek alle dinge tot hom:

"Als de ziele luistert,

spreekı het al een taal dat leeft",

Enige aardse gegewe, bv. 'n boom, kan 'n simboliese betekenis verkry. Tolius herinner in sy keuse van byvoorbeeld die treurwilgerboom ook aan die Nederlandse digter Willem de Merode, wat in sy gedig "Besneeuwde treurwilg" homself met die wilgerboom vergelyk:

"Ik ben een boom des Heeren,

Die weder groenen zal."

Die digter beskryf die gedaantes wat hy lewend voor hom sien, "hij ziet met een het ding in al zijn relatien". Natuurlik moet die digter woorde gebruik, en hulle is soos sy geesteskinders. Maar dit gebeur eers nadat hy gesien het. Wie nie hierdie dieper insig het nie, kan volgens Totius nie digter wees nie, al gebruik hy ook hoeveel mooi woorde: "Wie niet gezien heeft, kan niet dichten, ook al stapelt hij de woorden torenhog, ook al imponeert en overweldigt hij".

\subsection{Eise Aan Die Digstof (objek)}

Tot sover die digter. In die tweede gedeelte van die referaat handel Totius oor die digstof of objek soos hy dit noem. Die alledaagse, sienlike dinge is die digter se boust of, "dit is zijn objekt".

Die sienersoog roep na die sienlike. Die sienlike dinge om die digter is draers van 'n goddelike gedagte: "Het wereldleven om hem heen is geen schijn, maar drager van de gedachte Gods". Totius stem saam met Herder, wat beweer: "Het gans heelal, met al zijn bewegingen en gedaanten, is ... beelden, die op hem werken", en Rabus, wat sê: "Die Natur ist allenthalben durchwaltet von einer plastischen Thätigkeit".

"leder Scheppingsding draagt een idee", beweer Totius, en dit vorm die kern van die simboliek in sy poësie. Die ware digter sien as ' $t$ ware deur tralies heen toldat alle "uitwendige dofheid wegschitteren". Die aardse dinge word weergegee in "de fotografie van het woord".

Totius sien as 'n tekort in Kloos se poësie dat hy nie hierdie wêreldbeskouing 


\section{Van Deventer}

besit het nie. Totius verwys na die grootste digters in die wêreldliteratuur, na Dante, Milton en Vondel, vir wie die wêreld vol was "van de gedachte Gods". Hierdie godvresende digters het telkens na die Bybel teruggegryp, en hy wys daarop dat dit nooit vir hulle 'n teensinnige onderwerping was nie ('n gaan na Canossa).

Vir hierdie groot digters, soos ook vir Lessing, was die lewe en beweging kenmerke van die ware poësie. Die digter jaag nie dooie abstraksie na nie maar lewende dinge wat "wandelen, dansen, springen en zingen voor zijn verhelderd oog". Dit kan vergelyk word met Totius se verwysing vroeër in die artikel na die eerste mens, wat die gedierte gesien het "in zijn beweging, gratie, vrolikheid, zang en geluid" en naam daaraan gegee het.

Vervolgens wys Totius daarop dat dit die digter se taak is om sy siening aan ander oor te dra, ander wat nie die gawe van hierdie digterlike insig besit nie: "en het is zijn taak ook anderen de schellen van de ogen te doen vallen opdat ook zij mogen genieten wat hij geniet en aanschouwen wat hij aanschouwt". Die kunstenaar moet ander laat deel in hicrdie gawe wat hy ontvang het; die digter as begenadigde moet hierdie dieper insig aan ander oordra. En hiermee sluit Totius aan by die derde deel van sy referaat, naamlik die taak van die digier.

\subsection{Eise Aan Die Digkuns (eenheid van objek en subjek)}

Die derde en laaste gedeelte van die lesing handel, in aansluiting by die vorige, oor die digkuns en die digter se taak.

Naas die sienersbeeld (die digter is siener, die voorwerp die gesiene en die digterstaak die siening) vergelyk Totius die digter hier ook met die beeldhouer (digter). Net soos die beeldhouer sy grondstof gebruik en dit met beitel en hammer vorm, so vorm die digter sy stof orm tot 'n gedig. Waar die beeldhouer egter met hammer en beitel werk, is die digter se instrument "het heerlik instrument van de taal".

Dic sicnersgawe alleen is nie van belang nie, dit verkry eers gewig by die uiteindelike doel, naamlik "het uitbrengen in het volle daglicht van die schuchtere inwendigheid". Die gedig is die kunstige verwerking en afwerking van wat die digter gesien het: van wat "voor de schouwende dichtergeest opdoemt". Die beeld is vir Totius die skakel tussen die digter en die skepping. Die gedig is die "kunstvaardige afwerking in de schoonheidsfantasie van het geziene".

Hierdie omskeppingstaak van die digter is nie maklik nie: dit is 'n uiters 


\section{Totius}

moeilike taak. Die digter moet die kuns met pyn baar ("om de kunst te baren met wee"). Dit is 'n "moeizame weg", want hy moet die ewigheidsgedagte wat in die skepping "ingewrocht" is, daaruit verlos. Die aardse ding moet tot die gepaste vorm "doorworstelt" word, soos Totius Vermeylen aanhaal. Maar tog is hierdie worsteling 'n "worsteling in liefde". Die uiteindelike produk word dan 'n "kunstvaardige afwerking" van die gesiene beeld.

Nie nel die oog is van belang nie, maar ook die oor is onontbeerlik. Met die oog moet die digter die dieper waarheid in die alledaagsheid sien, en dan moet hy die oor gebruik totdat 'n welluidende vorm verkry is.

Die digter moet sy gehoor inspan om die gedig te vervolmaak. "Een horend oor en een ziend oog, heeft de tlere gemaakt, ja die beide", haal Totius 'n ou spreekwoord aan. Beide oog en oor is belangrik, en albei is 'n Godsgawe: "Die beide zijn de charismata van de dichter bovell andere mensen". Mel die oog sien die digter die goddelike waarhede, waarhede wat in die skepping verborge is, en met die oor moet hy die "zingend woord" verander totdat die regte vorm verkry is.

Dit is volgens Totius sy digterlike taak: hy moet "die verhewe gedagtes wat hy 'sien', vaslê in die woord: hy moet as 't ware ander laat 'sien' wat hy 'sien'" (Pretorius, 1977: 4). "Alleen die digter is deur die verhelderende oog en oor bo ander mense begenadig. . . Maar met hierdie begenadiging gaan vir die digter ook 'n besondere opdrag gepaard, naamlik om ook ander mense te laat sien wat hy sien" (Cloete, 1961: 96).

Hier verskil Totius in opvatting en werkswyse van 'n groot aantal ander digters, wanneer hy beweer dat die uiteindelike produk of kunswerk ' $n$ afskynsel moet wees van die Goddelikheid waaruit dit ontstaan.

Die kuns is vir Totius die draer van die gedagte van God: "Hel wêreldleven om hem heen is geen schijn maar drager van de gedachte Gods". Dil kan volgens Totius ook nie anders nie, want uit die genade van God ontstaan die kunswerk, daarom is die kunswerk 'n belangrike deel van die dankbaarheid teenoor die Skepper, wat alles so mooi gemaak het ("een voornaam stuk ter dankbaarheid jegens Hem, die alles so schoon heeft gemaakt").

Aan die einde van sy referaat haal Totius sy Amsterdamse professor, prof. Woltjer, instemmend aan: "Het begin en einde van alle poëzie is de ere Gods in het woord Hem toegebracht uit en door zijn schepsel"

Die kunstenaar beoefen volgens Totius sy kuns dus nie slegs om die genot daarvan nie maar omdat hy nie anders kan as om sy dankbaarheid teenoor sy 


\section{Van Deventer}

Skepper op hierdie manier te bewys nie.

In hierdie verband is al verwys na Opperman se bekende kwatryn "In memoriam", wat oor Totius handel. Die woorde ". . Afrika se klip en kraal/ (sal) herinner ... hoe grool Hy is", dui op die opvatting dat God in sy poësie verheerlik moet word. "Om die volk te herinner hoe 'groot Hy is', is die kern van Totius se roeping as Calvinis" (Pretorius, 1977: 6)

"Totius die denker en idealis is die Calvinistiese siener wat in sekere woorde 'n boodskap aan sy volk wou bring" (Buning, 1934: 173). "Die belydenis: 'Aan God alleen die eer', loop soos 'n goue draad deur sy skeppingswerk" en “Hy was die digter by die grasie van God. Hy was die gelowige siener wat reeds in hierdie lewe in die lig van God se Woord die onsienlike sigbaar wou maak", sê Van Vuuren (1977: 30).

Die uiteindelike doel van sy poësie, soos Totius dit sien, is die verheeliking van sy Skepper. Totius "sien dit in die Raadsplan van God, wat groots en luisterryk is en wat die belofte van die heerlike toekoms inhou vir hom wat glo" (Venter 1977: 136).

\section{UIT DIE TOTIUSBOEKERY}

Uit die boeke uit Totius se boekery blyk dit dat hy ook dikwels oor die aard van die profeet gelees het en dat dit sy siening van die profeet beinvloed het. Totius het dikwels oor die pofeet Jesaja gepreek, en in sy boekery is 'n groot aantal boeke wat oor hierdie profeet handel.

In Totius se eksemplaar* van G. Ch. Aalders se De Profeten Des ouden verbonds is sekere paragrawe oor die aard van die profeet onderstreep of in die kantlyn gemerk. Die woord nabi is in die oorsetting van die Latynse Vulgata vir die begrip profeet gebruik. Nabi beteken spreker vir ' $n$ ander of tolk (kyk in hierdie verband Ex. 7: 1: 4:16: Jer. 1:5). Die profeet of nabi is 'n tolk van 'n hoër mag wat met die Godheid in verband gebring word: "De nabi is altoos de spreker die het woord van God vertolkt".

Die roeping van die profeet is die oordra van Gods Woord: "De dienst der profeten bestaat dus in het overbrengen van Gods Woord". Hy is "bode Gods".

Die profeet is ook "voorspreker in rechtszaken, advocaat en tevens politicus, in zekeren zin selfs diplomaat" (Aalders 1918: 16). Die woord politikus in

- Ians in die Totiusboekery, Totiushuis, Potchefstroom. 
hierdie boek is onderstreep en NB is in die kantlyn ingeskrywe. 'n Ander naam vir profeet is ro'eh of chozeh, wat in die Statevertaling met ziener of schouwer vertaal is (kyk ook Jes. 30: 10). Samuel word "de ziener bij uitnemendheid" genoem (Aalders, 1918: 12)

Uit Aalders se boek blyk ook duidelik die verband lussen die profeet en die digter. Aalders (1918: 10) sê: Israël's religieuze poëzie draagı niet minder een openbaringskarakter dan de redenen der profeten" en: "De gewijde dichter en zanger is veelal evenzeer een spreeker van die woorden Cods als de nabi" (Aalders, 1918: 99).

Die profeet of digter se taak is "aanschouwing met het geestelijke oog" (Aalders, 1918: 12). Ook in Totius se eksemplaar van prof. L. Rabus se Logik Und System Der Wissenschaften is gedeeltes oor die verband tussen beeld en dieper idee onderstreep.

Die woorde "Die Natur ist allenthalben durchwaltel von einer plastischen Thäligkeit" word ook deur Totius in sy artikel oor die digter as siener aangehaal. "Die Bilder nun, welche die Phantasie woher immer schöpft, sind thatsächlich der nächste Anlass, Gegenstand und Inhalt für das Denken", sê prof. Rabus verder. Die denke openbaar die dieper denkbeeld wat reeds in die beeld verborge is: " . . dass vielmehr das Denken als eine schon im Bilde verborge wirkende Thatigkeit zu fassen ist..." (Rabus, 1895: 56).

Die natuur is nie vanself skoon nie maar word betekenisvol deur die betragting van die mens: "schon darum darf man behaupten, dass die Natur nicht an sich bereits schön ist, sondern dass sie es wird durch die personifizierende Phantasie des Menschen" (Rabus, 1895: 330).

Die verganklike natuur word betrag totdat dit 'n dieper waarheid afstaan: "Das eine der Prinzipien ist Naturprinzip: die Erwägung der vergänglichen Natur führt zu Annahme einer ewigen Natur..." (Rabus, 1895: 343). Hierdie woorde is in Totius se eksemplaar onderstreep (deur Totius?) en met 'n NB gemerk.

In verband met die vraag hoe wat stoflik is, in die denke opgeneem word, verenig Totius hom met Rabus (1895: 329) wat sê: "Sinnliches Natur und geistiges Leben bilden in der Phantasie ein Ganzes, fur sich, das als ein Mittelglied zwischen beiden hin und herwebı, eine sich entwichelnde Bilderwelt".

Totius se rede by die aanvaarding van die hoogleraarsamp in die teologie aan die teologiese skool op Potchefstroom, de zestiende-eeuwse profetie en haar betek enis voor onze tyd, werp verder lig op sy siening van die profeet. Soos sy Amsterdamse leermeester, prof. Woltjer, verwys, Totius ook in sy intreerede 


\section{Van Deventer}

na die aard en wese van die profeet van God. Die gawe van die profeet is volgens Totius "niet de gave om toekomende dingen te voorspellen ... maar het recht verstand van de $\mathrm{H}$. Schrifture uit te leggen en tot vertroosting en vermaning van de gemeente toe te passen". Die taak van die profeet is verduideliking van die Skrif : "Hel profeteren is nu niet meer hel uilzeggen van nieuwe, pas geopenbaarde dingen, maar de bezielde prediking en 'geestelike geniale' uillegging der H. Schriftuur".

Uit die aangehaalde gedeeltes blyk dit dat Totius dikwels oor die aard van die profeel gelees en nagedink het. Hy sien die profeet nie as 'voorspeller' nie maar as verklaarder van die aardse dinge. Die profeet sien in die aardse dinge dieper geestelike waarhede, en dit is sy plig om hierdie waarhede aan sy lesers oor te dra.

\section{SAMEVATTING}

In Totius se referaat op die jaarvergadering van die Suid-Alrikaanse Akademie vir Wetenskap en Kuns in 1911 word sy siening van die digtersk ap soos nêrens anders in sy werk nie uileengesit. Hierdie opstel kan as die begin van die Afrikaanse lieterêre teorie beskou word.

In hierdie lesing sit Totius sy siening omtrent die simboliseringsproses in die poësie uiteen en gee hy sy mening omtrent die digter as Calvinisiese siener wat in die aardse, sienlike dinge 'n dieper waarheid vind.

Die digter moet noukeurig op die aardse dinge let, hy moet $X$-straaloë hê en 'n duidelike visie besit. In die gewoon alledaagse vind die digter dieper, verborge waarhede.

Alle aardse dinge is geskik om as digstol te dien, niks is te gering nie, want elke skeppingsding is deur die Skepper geskep, is 'skoon en waar' en dra daarom 'n idee. Die subjek van die gedig bepaal ook nie of die gedig goed of swak sal wees nie.

Die digter moet met sy instrument van die taal die dieper waarheid uit die aardse gegewe bevry. Dit is 'n moeilike proses, waarin die oog sowel as die oor gebruik word. So word die verhewe gedagtes in die woord vasgelè.

Dit is volgens Totius die digter of siener se roeping om hierdie verhewe waarhede aan ander oor te dra. Vir hierdie siening kan ook bewyse gevind word in Tolius se boekery en in ander werk van hom, bv. sy rede by die aanvaarding van die hoogleraarsamp op Potchefstroom. Die kunswerk sal ook altyd die stempel dra van die Goddelikheid waaruit dit ontstaan het. 
Totius

Die digter en in die besonder die Calvinistiese profeet en siener is siener, verklaarder en oordraer van die dieper geestelike waarhede wat in alle aardse verskynsels te vinde is.

\section{BIBLIOGRAFIE}

AALDERS, G.Ch. 1918. De profeten des ouden verbonds. Kampen: I.H. Kok.

BUNING, Tj. 1934. Die tegniek van Totius. Ons Tydskrif, 2 (1), April.

CLOETE, T.T. 1978. Totius se organiese beskouing. Langenhovengedenklesing, U.P.E.

CLOETE, T.T. 1961. Die wêreld is ons woning nie. Kaapstad: Tafelberg.

DEKKER, G. 1964. Afrikaanse literatuurgeskiedenis. Kaapstad: Nasou.

DU TOIT, J.D. 1911. De zestiende-eeuwse profetie en haar betekenis voor onze tijd. Rede gehouden bij de aanvaarding van het hoogleeraarsambt in de theologie aan de theologiese school te Potchefstroom op Zaterdag 15 April. Potchefstroom: Koomans.

HARIMAN, E. 1931. Totius se lewensbeskouing soos weerspieël in sy gedigte. Nuwe Brandwag, 3 (3), Augustus.

HUISCENOOT. Totius-gedenknommer. Deel XXXI, nr. 1300.

LOUW, N.P. van WYK. 1939. Berigte te velde. Kaapstad: Nasionale Boekhandel.

NIENABER, P.J. red. 1948. Totius. Digter en profeet. Johannesburg: APB.

OPPERMAN, D.J. 1947. Die digter Totius. Standpunte, 2(2): $22 \mathrm{ev}$. April. (later as "Totius: 'n digterlike dialektiek" in OPPERMAN, D.J. 1959. Wiggelstok. Kaapstad: Nasionale Boekhandel en ook in SCHOLIZ, Merwe red. 1977. Die lewende Totius. Kaapstad: Tafelberg).

PRETORIUS, C.E. 1977. Totius: 21 Februarie $1877-21$ Februarie 1977. Tydskrif vir letterkunde, 15 (4), p. 1 e.v., November. 


\section{Van Deventer}

RABUS, L. 1895. Logik und System der Wissenschaffen. Leipzig: Deichert. SCHOLTZ, Merwe red. 1977. Die lewende Totius. Kaapstad: Tafelberg. TOTIUS. 1977. Totius versamelde werke. Kaapstad: Tafelberg. TOTIUS. 1960. Versamelde werke van J.D. du Toit (Totius) Johannesburg: Dagbreek.

VAN DEN HEFVER, C.M. s.j. Keur uit die gedigte van Totius. Bloemfontein: Nasionale Boekhandel.

VAN DER MERWE, D.C.S. 1977. Totius as leoloog. Koers, 42 (1): 66.

VAN RENSBURG, F.I.J. 1977. Kanttekening by 'n literêre teorie. (In SCHOLTZ, Merwe red. 1977. Die lewende Totius. Kaapstad: Tafelberg.)

VAN VUUREN, I.L.). 1977. Die digter Totius. (In VENTER, E.A. red. Totius 1877 - 1977. Potchefstroom: $P \mathrm{U}$ vir $\mathrm{CHO}$ ).

VENTER, H. 1977 a. Totius . . " In VAN RENSBURG, F.I.J. samest. Totiuskroniek. Kaapstad: Tafelberg.

VENTER, H. 1977 b. Het Totius vandag nog iets te sê? Koers, 42(5): e.v. 374.

VENTER, H. 1977 b. Het Totius vandag nog iets te sê? Koers, 42(5): e.v. 374.

WOLTJER, J. 1896. Ideëel en reëel. Rede bij overdracht van het rectoraat aan de Vrije Universiteit op 28 October 1901. Leiden: Donner.

WOLTJER, J. 1901. Beginsels en norm in de litteratuur. Rede bij de overdracht van het rectoraat aan de Vrije Universiteit op 28 October 1901. Leiden: Donner. 